Available online at: https://proceeding.researchsynergypress.com/index.php/cpmhs/index

RSF Conference Series: Medical and Health Science

e-ISSN (to be processed) / p-ISSN (to be processed)

Volume 1 Number 1 (2021): 1-8

\title{
The Correlation between Anxiety and Insomnia Levels to Families of Health Workers during COVID-19
}

\author{
Noripansyah ${ }^{1}$, Lily Nabila Amar ${ }^{2}$ \\ ${ }^{1}$ Postgraduate of Human Resource Development, University of Airlangga, Indonesia \\ ${ }^{2}$ Health Office, Indonesia
}

\begin{abstract}
There are 5,197 positive confirmed cases of COVID-19 in Banjarbaru. It is known that the COVID-19 pandemic causes essential problems related to basic needs such as economic, social, shelter and nutrition, as well as the physical effects of the disease. Not only health workers but also families of health workers experience psychological pressure. In a preliminary study, it was found that the family feel worried and anxious about their families members who work in a hospital to take care of patients. This research aims to investigate the correlation between anxiety levels and insomnia in family members of health workers at Idaman Hospital, Banjarbaru, during the COVID-19 pandemic. This research uses a Cross-Sectional approach using social media with the google form platform taking 125 correspondence as a sample. The research instrument used the DASS-21 and Insomnia Severity Index. The data were analyzed using the SPSS program, with the Spearman rank correlation test working by testing the associative hypothesis of two ordinal scale variables (ranking). A total of $70.4 \%$ of family members of health workers at Idaman Hospital Banjarbaru have a very severe level of anxiety. In addition, $46.4 \%$ of the families of health workers at Idaman Hospital Banjarbaru experienced severe insomnia. The correlation for state anxiety-insomnia is 0.846 with a $\mathrm{p}$-value $=0.000(\mathrm{p}<0.05)$. This indicates that the two variables have a significant relationship with moderate correlation strength. The direction of the positive correlation indicates that these two variables move in the same direction, meaning that the higher the anxiety, the higher insomnia is experienced. Due to the COVID-19 pandemic, the population was limited. It is necessary to conduct further and comprehensive research on the psychological impact on family members of health workers. It is very limited to find research that examines the psychological condition of the family of health workers because, as we know, that not only affects the health workers themselves, but the family also experiences psychological impacts.
\end{abstract}

Keywords: COVID-19; anxiety; insomnia; health workers

\section{INTRODUCTION}

Not only health workers, families of health workers such as husbands or wives for those who are married as well as children, as well as parents of health workers for those who are not married also experience problems. Fear of the consequences of a fatal illness, combined with severe anxiety and mental stress, which can coincide with insomnia and the physical effects of illness, can create unfavourable conditions for both health workers and their families and those around them due to worsening mental health disorders (Xiang YT, 2020) At the start of the SARS epidemic, health workers caring for patients in hospitals expressed concerns such as fear, loneliness, fatigue, and anger.

All health workers are compared to health workers who are facing tremendous stress due to COVID-19, especially those related to suspected or confirmed cases due to the high risk of infection, inadequate protection, lack of experience in disease control and management, long working hours. Family

Corresponding author

Noripansyah, noripansyah-2020@pasca.unair.ac.id

DOI: (to be processed)

Research Synergy Foundation 
support is no exception closely related to the work of the health worker; it is not uncommon for health workers to actually experience psychological problems. Many studies have been conducted on the psychological impact experienced by health workers during the COVID-19 pandemic; examples of findings from Benjamin YQ Tan, MD (2020) found that $68(14,5 \%)$ health workers were screened positively for anxiety, 42 (8.9\%) for depression, 31 (6.6\%) for stress, and 36 (7.7\%) for clinical PTSD problems.

However, it is very rare to find research that examines the psychological condition of the family of health workers because as we know that not only has an impact on health workers themselves but families also experience psychological impacts, for example, families who have excessive anxiety and worry because health workers must contact directly with patients and there is no guarantee that workers will be immune from the COVID-19 virus, not to mention the longer working hours of health workers causing less time with family.

Families will experience depression, stress. In a previous preliminary study, by conducting interviews with several family members of COVID-19 Health Officers in the Banjarbaru City area, it was found that they experienced a lack of sleep due to anxiety about their health conditions and the risks of their families who work directly in charge of handling COVID-19 at the hospital. A more comprehensive understanding of the psychological burden on families of health workers during the COVID-19 pandemic is critical to providing psychological support that supports, improves and strengthens mental health services.

This research aims to investigate the relationship between anxiety levels and insomnia in family members of health workers at Idaman Hospital, Banjarbaru, during the COVID-19 pandemic.

H1: The Effect of Anxiety Due to Covid-19 on Insomnia Levels in Families of Covid-19 Health Officers.

\section{LITERATURE REVIEW}

\section{Anxiety}

Definition Anxiety

Anxiety is a common feeling when someone experiences fear or lose confidence because they do not know its source or form (Wiramihardja, 2005). According to Kaplan, Sadock, and Grebb (Fauziah\&Julianti, 2007), anxiety is a response to certain threatening situations, common phenomena that occur during development, change, and experiences, new or unprecedented experiences. Identity, self, the meaning of life. Anxiety is a reaction that can be felt by anyone. However, excessive anxiety, especially when in trouble, can interfere with the functioning of a person's life.

Anxiety usually occurs over a period of time and mainly depends on a person's life experiences. Special events and situations can hasten the onset of anxiety attacks. According to Savitri Ramaiah (2003:11), several factors cause anxious reactions:

Environment

The environment or surroundings of residence affect the way individuals think about themselves and others. This is due to unpleasant experiences for individuals with family, friends, or co-workers so that the individual feels insecure about his environment.

\section{Repressed emotions}

Anxiety can occur if the individual is unable to find a way out for his own feelings in this personal relationship, especially if he suppresses anger or frustration for a very long time. 
Physical causes

The mind and body are constantly interacting and can cause anxiety. This is seen in conditions such as pregnancy, during adolescence and when recovering from an illness. During these conditions, mood swings are common, and these can cause anxiety.

\section{Insomnia}

Insomnia is a sleep disorder that most often occurs and is best known by the public. Insomnia is difficulty initiating or maintaining sleep. Usually, patients with insomnia often have complaints that are not specific, in addition to complaints of insomnia itself (Kaplan et al., 2010). This disorder can be temporary or permanent. Brief or transient periods of insomnia are most often due to anxiety. In comparison, persistent insomnia is a condition that is quite often found with the most frequent problem, namely difficulty falling asleep (Sadock B. \& Sadock V., 2014). Insomnia can also be divided into three types based on the duration of occurrence, namely transient insomnia that only lasts 2 to 3 days, short-term insomnia lasts up to 3 weeks, and long-term insomnia that can occur for a longer time, this is usually caused by certain medical or psychiatric conditions (Maslim, 2007). Complaints of sleep disorders can actually occur at any age, but the prevalence of insomnia itself tends to increase in the elderly, this is also associated with increasing age and the presence of various other causes. In a study conducted on 5886 elderly people aged 65 years and over, it was found that more than $70 \%$ of the elderly experienced insomnia (Bestari, 2013). Other factors associated with an increased prevalence of sleep disorders are the female gender, the presence of mental or medical disorders and substance abuse (Kaplan et al., 2010). It was also reported that approximately $40-50 \%$ of the elderly population experience this (Anwar, 2010). The following risk factors can cause insomnia. The following is an explanation of the risk factors that influence the occurrence of insomnia:

1. Age

2. Gender

3. Medical and psychiatric conditions

4. Environmental and social factors

As a result, negative psychological effects include symptoms of post-traumatic stress, confusion, and anger. Increased stressors, as quarantine durations are longer, fear of infection, frustration, boredom, inadequate supplies, lack of information, financial loss, and unsettling societal stigma.

\section{The Relationship between COVID-19 and Psychological Conditions}

The impact of the COVID-19 pandemic is not only causing the number of infections to continue to grow but also triggering great fear, concern and concern in the population. Epidemiologically, infectious diseases not only affect the physical health of patients but also affect the psychological health and wellbeing of the uninfected population. It has been shown that the prevalence of new infectious diseases, such as severe acute respiratory syndrome (SARS), can increase anxiety, depression, and stress levels in the general population. These negative emotions also affect sleep quality (Xiao et al., 2020).

\section{RESEARCH METHOD}

In this study, the researcher used a cross-sectional approach by using social media with the google form platform. Cross-sectional research is a study to study the dynamics of the correlation between risk factors and effects by means of approach, observation, or data collection. The cross-sectional study was only observed once, and measurements were made on the subject variables at the time of the study 
(Notoatmojo, 2010). In this study, researchers describe the effect of Covid-19 on the mental health (insomnia, depression, anxiety, and stress) of the families of health workers. This study uses a correlation technique to determine the direction and data collection that will be carried out in this study using the questionnaire method. In the questionnaire method, a questionnaire is used as a data collection tool which will previously be tested for validity and reliability.

The research variables used in this study consisted of two variables, namely one independent variable and one dependent variable. These variables are:

Dependent variable (Y): Insomnia level (mild, moderate, severe) family of health workers who handle COVID-19.

Independent variable (X): Stress and Anxiety due to the COVID-19 Pandemic in Families Health workers dealing with COVID-19

Testing the hypothesis of this research is done by finding the coefficient of the relationship between variable $\mathrm{X}$ to variable $\mathrm{Y}$.

In this study, the population is the entire family of health workers who are specialized to treat patients exposed to the COVID-19 virus. Inclusion criteria are respondents who have families who work as health workers at IDAMAN Hospital, Banjarbaru City and are willing to be research respondents. Exclusion criteria in this study were respondents who did not complete the research instrument and who did not live at home with health workers at IDAMAN Hospital in Banjarbaru City who handled COVID-19. To collect data, the researcher will take the total number of samples taken is 125 people (family members).

To collect research data, the author uses instruments in the form of DASS-21 and the Insomnia Severity Index. Analysis of the data in this study using the Spearman Rho statistical test. This test is used to determine the significance of the relationship between the independent and dependent variables with a numerical scale with a significance level of $=0.05$. This means that if the statistical test results show $p$ $<0.05$, then there is a significant relationship between the independent variable and the dependent variable. In addition, this correlation test is used to determine the direction of a relationship. The positive sign (+) indicates the direction of a positive relationship, which means that if the dependent variable is high, the independent variable is also high. While the negative sign (-) indicates the direction of the negative relationship, which means that if the dependent variable is high, the independent variable will decrease and vice versa.

\section{FINDINGS AND DISCUSSION}

\section{Results}

Descriptive Analysis

Description of the Anxiety Level of Family Health Workers at Idaman Hospital Banjarbaru during COVID19

Based on the results of research that has been carried out on families of health workers at Idaman Hospital Banjarbaru during the COVID-19 pandemic, the anxiety levels of family members can be grouped into five categories, namely; normal, mild, moderate, severe, very heavy categories. Anxiety categories of family members of health workers can be seen in the following table: 
Table 1. Anxiety Level

\begin{tabular}{|ll|l|l|l|l|}
\hline & Frequency & Percent & $\begin{array}{l}\text { Valid } \\
\text { Percent }\end{array}$ & $\begin{array}{l}\text { Cumulative } \\
\text { Percent }\end{array}$ \\
\hline \multirow{6}{*}{ Valid } & Normal & 19 & 15.2 & 15.2 & 15.2 \\
& Light & 7 & 5.6 & 5.6 & 20.8 \\
& Currently & 7 & 5.6 & 5.6 & 26.4 \\
Heavy & 4 & 3.2 & 3.2 & 29.6 \\
Very heavy & 88 & 70.4 & 70.4 & 100.0 \\
Total & 125 & 100.0 & 100.0 & \\
\hline
\end{tabular}

Based on the category of the table above, there are 88 correspondents (70.4\%) who are in a very severe level of anxiety, four correspondence (3.2\%) in weight level, seven correspondence (5.6\%) in moderate level, seven correspondence (5.6\%) in the mild level, and19 correspondence (15.2\%) within the normal level. So it can be concluded that the family of health workers at Idaman Hospital Banjarbaru have a very heavy level of anxiety.

Description of the Insomnia Level of the family of health workers at the Banjarbaru Idaman Hospital during COVID-19

Based on the results of research that has been conducted on families of health workers at Idaman Hospital Banjarbaru, the level of insomnia in family members can be grouped into four categories, namely: No insomnia, borderline insomnia, moderate insomnia, severe insomnia.

Table 2. Insomnia Level

\begin{tabular}{|ll|l|l|l|l|}
\hline & Frequency & Percent & Valid Percent & $\begin{array}{l}\text { Cumulative } \\
\text { Percent }\end{array}$ \\
\hline \multirow{4}{*}{ Valid } & & & & 14.4 \\
& No Insomnia & 18 & 14.4 & 14.4 & 29.6 \\
Moderate Insomnia & 19 & 15.2 & 15.2 & 53.6 \\
Severe Insomnia & 30 & 24.0 & 24.0 & 100.0 \\
Total & 58 & 46.4 & 46.4 & \\
\hline
\end{tabular}

Based on the table categories above, there are 58 correspondents (46.4\%) who have severe insomnia30 correspondents (24\%) had moderate insomnia, 19 correspondents $(15.2 \%)$ had mild insomnia, 18 correspondents (14.4\%) did not experience insomnia. So it can be concluded that the family of health workers at Idaman Hospital Banjarbaru experienced severe insomnia.

\section{Normality test}

The data normality test is intended to determine whether the data is normally distributed or not. The data normality test in this study was intended to test the variables of COVID-19, anxiety, and insomnia. Testing the normality of the data in this study using the SPSS 21 program through the testKolmogorovSmirnov. 
The Kolmogorov Smirnov test is used to compare the distribution of the data (which will be tested for normality) with the standard normal distribution. The application of the Kolmogorov Smirnov test is that if the value of Sig. below 0.05 means that the data to be tested has a significant difference with standard normal data, meaning that the data is not normal. If the value of Sig. above 0.05 , then there is no significant difference with the standard normal data, which means the data is normal. The following are the results of the normality test obtained from the tested variables.

Table 3. Tests of Normality

\begin{tabular}{|l|l|l|l|l|}
\hline \multirow{2}{*}{} & \multicolumn{3}{|l|}{ Kolmogorov-Smirnova } & Information \\
\cline { 2 - 4 } & Statistics & Df & Sig. & \\
Anxiety_Level & 429 & 125 & 000 & Normal \\
Insomnia & 277 & 125 & 000 & Normal \\
\hline
\end{tabular}

a. Lilliefors Significance Correction

\section{Inferential Analysis}

The presence or absence of a relationship between anxiety and insomnia with the COVID-19 pandemic on family members of health workers at Idaman Hospital Banjarbaru. Then in the process, researchers use Pearson Correlation.

Table 4. Pearson Correlations

\begin{tabular}{|l|l|l|l|}
\hline & & Anxiety_Level & Insomnia \\
\hline \multirow{3}{*}{ Anxiety_Level } & Pearson Correlation & 1 & $846^{* *}$ \\
& Sig. (2-tailed) & & 000 \\
& N & 125 & 125 \\
\hline \multirow{3}{*}{ Insomnia } & Pearson Correlation & $846^{* *}$ & 1 \\
& Sig. (2-tailed) & 000 & \\
& N & 125 & 125 \\
\hline
\end{tabular}

**. Correlation is significant at the 0.01 level (2-tailed).

So it can be concluded that the Pearson correlation for state anxiety-insomnia is 0.846 with a pvalue $=0.000(p<0.05)$; this indicates that the two variables have a significant relationship with moderate correlation strength. The direction of the positive correlation indicates that these two variables move in the same direction, meaning that the higher the anxiety, the higher insomnia is experienced.

\section{Discussion}

Based on the findings through a questionnaire that has been distributed via Google Form, it was found that family members of health workers who have a direct role in handling COVID-19 at the Idaman Hospital Banjarbaru experienced a severe level of anxiety, this was due to several factors, such as seeing the dangers that threatened to occur. Himself and his family (Kholil Lur Rochman, 2010:167). This anxiety is closer to the fear that family members who work as health workers handling COVID-19 contract this dangerous virus. Moreover, in the last two weeks, almost 80 percent of the health workers at the Idaman hospital were exposed to the Coronavirus. As a result, this feeling of uncertainty often causes or destroys uncomfortable physiological changes (Kholil Lur Rochman, 2010: 104). If not treated immediately, 
This severe anxiety disorder will affect the physical condition of the family members of the health workers, such as lack of hours of sleep, as well as poor sleep quality due to the uncomfortable feeling experienced by the family members of the health workers.

Difficulty initiating or maintaining sleep is usually referred to as insomnia. Insomnia was experienced by many surrounding communities during the COVID-19 pandemic, the level of acute insomnia was experienced by most of the families of health workers in charge of handling COVID-19 cases. Brief or transient periods of insomnia are most often due to anxiety. Meanwhile, persistent insomnia is a condition that is quite often found with the most frequent problem, namely difficulty falling asleep (Sadock B. \& Sadock V., 2014).

H1 = The Effect of Anxiety Due to Covid-19 on Insomnia Levels in Families of Covid-19 Health Officers.

The correlation for state anxiety-insomnia is 0.846 with a p-value $=0.000(\mathrm{p}<0.05)$; this shows that the two variables have a significant relationship with the strength of the correlation, which is classified as moderate. The direction of positive correlation indicates that these two variables move in the same direction. It can be concluded that anxiety disorders are closely related to insomnia found in the case of families of health workers in charge of handling COVID-19 cases, meaning that the higher the level of anxiety, the more insomnia experienced.

\section{CONCLUSION}

Nearly 80 people from family members of health workers experience high levels of anxiety; this also affects their sleep quality. Nearly 50 percent of them experience severe insomnia. Excessive concern about the health conditions of health workers who work to treat positive Covid-19 patients is increasing. Therefore, family members of health workers need to get great support from various parties, including the government and all aspects of society, in order to reduce psychological disorders that occur.

\section{REFERENCES} 1576.

Adler DA, M. T. (2006). Job performance deficits due to depression. Am J Psychiatry, 163(9):1569-

Andrea Fiorillo, P. G. (2020). The consequences of the COVID-19 pandemic on mental health and implications for clinical practice. The Cambridge Coronavirus Collection, 1-4.

Archard, D. (2010). The Family: A Liberal Defence. London: Palgrave Macmillan.

Dubey S, B. P. (2020). Psychosocial impact of COVID-19. Diabetes Metab Syndr Clin Res Rev, 14(5):779-788.

Gilmour H, P. S. (2007). Depression and work impairment. Health Rep, 18(1):9-22.

Hawari, D. (2001). Al-Qur’an Ilmu Kedokteran Jiwa dan Kesehatan Jiwa. Dana Bhakti Prima Yasa.

Ivanova JI, B. H. (2010). Direct and indirect costs of employees with treatment-resistant and nontreatment-resistant major depressive disorder. Curr Med Res Opin, 26(10):2475-2484.

Koerner, A. F. (2004). Communication in intact families. In A. L. Vangelisti Handbook of family communication. Mahwah, NJ: Lawrence Erlbaum.

Korsman, S. v. (2012). Viroloy. China: Churchill Livingston Elsevier.

Li W, e. a. (2020). Progression of Mental Health Services during the COVID-19 Outbreak in China. Int J Biol Sci, 16(10):1732. 
Lovibond, S. L. (1995). Manual for the Depression Anxiety \& Stress Scales. 2nd Ed. Sydney: Psychology Foundation.

Marcus M, Y. M. (2012). Depression: A global public health concern. WHO, Department of Mental Health and Substance Abuse. 1:6-8.

Mikkelsen, K. e. (2016). The effects of vitamin B in depression. Current medicinal chemistry 23 (38), 4317-4337.

Musa, R. F. (2007). Translation, Validation and Psychometric Properties of Bahasa Malaysia Version of the Depression Anxiety and Stress Scales (DASS). ASEAN J Psychiatry, 8 (2): 82-89.

Nova, N. a. ( 2012). "Analisis Tingkat Stress Wanita Karir dalam Peran Gandanya dengan Regresi Logistik Ordinal (Studi Kasus pada Tenaga Kerja Wanita di RS. Mardi Rahayu Kudus). Media Statistika, vol. 5, no. 1,37-48.

NOVOPSYCH. (2018). Depression Anxiety Stress Scales - Long Form (DASS-42). NovoPsych: Software for Administering Outcome Questionnaires to Clients for Psychologists.

Patel, V. (2001). Cultural factors and international epidemiology. Br Med Bul, 57:33-45.

Silaen, A. C. (2020). DAMPAK PANDEMI COVID-19 TERHADAP PSIKOLOGIS TENAGA KESEHATAN. $1-5$.

Students Against Depression. (2017). Anxiety; Depression Society of America; Psych Central. PsyWeb.com.

Usman A, A. Z. (2011). Work stress experienced by the teaching staff of University of the Punjab, Pakistan: antecedents and consequences. Int J Bus Soc Sci., 2(8):202-210.

Vindbjerg, E. d. (2019). Cross-Cultural Psychometric Properties of the Hamilton Depression Rating Scale. The Canadian Journal of Psychiatry, Vol. 64(1) 39-46.

Wahyuningsih, S. K. (2020). MODEL SISTEM PENDUKUNG KEPUTUSAN KELOMPOK UNTUK PENILAIAN GANGGUAN DEPRESI, KECEMASAN DAN STRESS BERDASARKAN DASS-42. Jurnal Teknologi Informasi dan Ilmu Komputer (JTIIK), 219-228.

WHO. (2003). Mental Health. Department of Mental Health and Substance Dependence.

Xiang Y-T, e. a. (2020). Timely mental health care for the 2019 novel coronavirus outbreak is urgently needed. Lancet Psychiatry., 7(3):228-9.

Zandifar A, B. R. (2020). Iranian mental health during the COVID-19 epidemic. Asian J Psychiatry, 51. 